University of Wollongong

Research Online

Australian Institute for Innovative Materials -

Papers

Australian Institute for Innovative Materials

$1-1-2014$

\title{
$\alpha$-Fe203/graphene nanocomposite as anode material for sodium-ion batteries with enhanced capacity retention
}

\author{
Zhijia Zhang \\ University of Wollongong, zz755@uowmail.edu.au \\ Yunxiao Wang \\ University of Wollongong, yw708@uowmail.edu.au \\ Shulei Chou \\ University of Wollongong, shulei@uow.edu.au \\ Huijun Li \\ University of Wollongong, huijun@uow.edu.au \\ Hua-Kun Liu \\ University of Wollongong, hua@uow.edu.au
}

See next page for additional authors

Follow this and additional works at: https://ro.uow.edu.au/aiimpapers

Part of the Engineering Commons, and the Physical Sciences and Mathematics Commons

Research Online is the open access institutional repository for the University of Wollongong. For further information contact the UOW Library: research-pubs@uow.edu.au 


\title{
$\boldsymbol{\alpha}$-Fe203/graphene nanocomposite as anode material for sodium-ion batteries with enhanced capacity retention
}

\author{
Abstract \\ Among the different energy storage systems, rechargeable lithium-ion batteries (LIBs) have been widely \\ applied in various portable electronic devices due to their high energy densities, long cycle life, and lack of \\ significant memory effect [1]. For wide-scale implementation of renewable energy, LIBs, however, face \\ challenges related to their safety, lifetime, and cost. Based on the wide availability and low cost of \\ sodium, sodium-ion batteries (SIBs) have the potential for meeting the demands of large-scale and \\ sustainable applications. Many cathode materials have been proposed, whereas only a few anode \\ materials have been investigated for SIBs [2]. The sodium ion (1.02 $\AA$ ) has a larger ionic radius than the \\ lithium ion $(0.76 \AA)$, so that graphite cannot be used as anode for SIBs [3]. There is less choice of anode \\ materials for SIBs. Transition metal oxides have been investigated as possible negative electrodes, relying \\ on insertion of $\mathrm{Na}+$ at low voltages. Valvo et al. reported that the electrochemical sodiation of \\ nanostructured $\mathrm{Fe}_{2} \mathrm{O}_{3}$ is reversible with the voltage range of $0.05-3.0 \mathrm{~V} v \mathrm{~s}$. $\mathrm{Na}^{+} / \mathrm{Na}$, and its specific \\ capacity is $350 \mathrm{mAh} \mathrm{g}^{-1}$ over 30 cycles at $40 \mathrm{~mA} \mathrm{~g}^{-1}[4,5]$. $\mathrm{Fe}_{2} \mathrm{O}_{3}$ requires further modifications, however, \\ to overcome its limitations for SIBs, such as poor electronic conductivity, volume variations, and related \\ cycling issues. To improve the electronic conductivity and capacity retention, we prepared $\alpha$ - \\ $\mathrm{Fe}_{2} \mathrm{O}_{3} / \mathrm{Graphene}$ nanocomposite using the ultrafast and environmentally friendly microwave autoclave \\ method [6].

\section{Keywords} \\ sodium, graphene, nanocomposite, fe2o3, anode, material, retention, capacity, enhanced, batteries, ion

\section{Disciplines} \\ Engineering | Physical Sciences and Mathematics

\section{Publication Details} \\ Zhang, Z., Wang, Y., Chou, S., Li, H., Liu, H. Kun. \& Wang, J. (2014). $\alpha-\mathrm{Fe}_{2} \mathrm{O}_{3} /$ graphene nanocomposite as \\ anode material for sodium-ion batteries with enhanced capacity retention. 17th International Meeting on \\ Lithium Batteries (pp. 1-2). The Electrochemical Society.

\section{Authors} \\ Zhijia Zhang, Yunxiao Wang, Shulei Chou, Huijun Li, Hua-Kun Liu, and Jiazhao Wang
}


Abstract: $\alpha-\mathrm{Fe}<\mathrm{sub}>2</ \mathrm{sub}>\mathrm{O}<\mathrm{sub}>3</$ sub $>/$ Graphene Nanocomposite as Anode Mat... Page 1 of 2

\section{The $17^{\text {th }}$ International Meeting}

on Lithium Batteries June 10-14, 2014 | Como, traly

278

a-Fe ${ }_{2} \mathrm{O}_{3} /$ Graphene Nanocomposite as Anode Material for Sodium-Ion Batteries with Enhanced Capacity Retention

Tuesday, 10 June 2014

Cernobbio Wing (Villa Erba)

Z. Zhang (Institute for Superconducting and Electronic Materials (ISEM), University of Wollongong), $Y$. Wang (Institute for Superconducting and Electronic Materials, University of Wollongong), S. Chou (University of Wollongong), H. Li (Faculty of Engineering, University of Wollongong), H. K. Liu, and J. Wang (University of Wollongong)

Among the different energy storage systems, rechargeable lithium-ion batteries (LIBs) have been widely applied in various portable electronic devices due to their high energy densities, long cycle life, and lack of significant memory effect [1]. For wide-scale implementation of renewable energy, LIBs, however, face challenges related to their safety, lifetime, and cost. Based on the wide availability and low cost of sodium, sodium-ion batteries (SIBs) have the potential for meeting the demands of large-scale and sustainable applications. Many cathode materials have been proposed, whereas only a few anode materials have been investigated for SIBs [2]. The sodium ion $(1.02 \AA)$ has a larger ionic radius than the lithium ion $(0.76 \AA)$, so that graphite cannot be used as anode for SIBs [3]. There is less choice of anode materials for SIBs. Transition metal oxides have been investigated as possible negative electrodes, relying on insertion of $\mathrm{Na}^{+}$at low voltages. Valvo et al. reported that the electrochemical sodiation of nanostructured $\mathrm{Fe}_{2} \mathrm{O}_{3}$ is reversible with the voltage range of $0.05-3.0 \mathrm{~V}$ vs. Na$/ \mathrm{Na}$, and its specific capacity is $350 \mathrm{mAh} \mathrm{g}^{-1}$ over 30 cycles at $40 \mathrm{~mA} \mathrm{~g}^{-1}$ $[4,5]$. $\mathrm{Fe}_{2} \mathrm{O}_{3}$ requires further modifications, however, to overcome its limitations for SIBs, such as poor electronic conductivity, volume variations, and related cycling issues. To improve the electronic conductivity and capacity retention, we prepared $\alpha-\mathrm{Fe}_{2} \mathrm{O}_{3} /$ Graphene nanocomposite using the ultrafast and environmentally friendly microwave autoclave method [6].

The $\alpha-\mathrm{Fe}_{2} \mathrm{O}_{3} /$ Graphene nanocomposite was analysed by field emission scanning electron microscopy (FESEM) and X-ray diffraction (XRD) to determine their morphology and structural properties. Graphene contents in the composites were determined by thermogravimetric analysis (TGA). $\alpha-\mathrm{Fe}_{2} \mathrm{O}_{3}$ nanoparticles are embedded in conductive and interconnected graphene networks [Fig 1(a)]. This nano-architecture increases the electronic conductivity and buffers volume change in $\alpha-\mathrm{Fe}_{2} \mathrm{O}_{3} /$ Graphene nanocomposite electrode. It can be observed in the XRD pattern in Fig. 1 that the $\alpha-\mathrm{Fe}_{2} \mathrm{O}_{3} / \mathrm{Graphene}$ nanocomposite has more broad peaks than the $\alpha-\mathrm{Fe}_{2} \mathrm{O}_{3}$ [Fig 1 (b)]. The electrochemical results show that the composite electrode containing $10 \mathrm{wt} . \%$ graphene has higher initial capacity recovery (69 \%) than the pure $\mathrm{Fe}_{2} \mathrm{O}_{3}$ electrode (59 \%) [Fig 1(c)] [4]. Moreover, the composite shows better capacity retention than in the reported results in the literature, retaining 401 $\mathrm{mAh} \mathrm{g}{ }^{-1}$ at current density of $40 \mathrm{~mA} \mathrm{~g}^{-1}$ after 30 cycles in the range of $0.05-2.60 \mathrm{~V}$ vs. Na $/ \mathrm{Na}$ [Fig 1 (d)] [3, 4].

References

[1] P. Poizot, S. Laruelle, S. Grugeon, L. Dupont, J.M. Tarascon, Nature 407(6803) (2000) 496.

[2] M.D. Slater, D. Kim, E. Lee, C.S. Johson, Adv. Funct. Mater. 23 (2013) 947.

[3] H. Xiong, M.D. Slater, M. Balasubramanian, C.S. Johnson, T. Rajh, J. Phys. Chem. Lett. 2 (2011) 2560.

[4] M. Valvo, F. Lindgren, U. Lafont, F. Björefors, K. Edström, J. Power Sources 245 (2014) 967.

[5] M.C. López, P. Lavela, G.F. Ortiz, J.L. Tirado, Electrochem. Commun. 27 (2013) 152.

[6] C. Zhong, J. Wang, Z. Chen, H. Liu, J. Phys. Chem. C 115 (2011) 25115.

Figure captions

Figure 1. (a) FESEM image and (b) XRD pattern of $\alpha-\mathrm{Fe}_{2} \mathrm{O}_{3} /$ Graphene nanocomposite with 10 wt.\% graphene; (c) discharge/charge curves of the selected cycles between 0.05 and $2.60 \mathrm{~V} \mathrm{vs}$. $\mathrm{Na}^{+} / \mathrm{Na}$ at a gravimetric current density of $40 \mathrm{~mA} \mathrm{~g}^{-1}$ for the $\alpha-\mathrm{Fe}_{2} \mathrm{O}_{3} /$ Graphene nanocomposite electrode with 
Abstract: $\alpha-\mathrm{Fe}<\mathrm{sub}>2</ \mathrm{sub}>\mathrm{O}<\mathrm{sub}>3</ \mathrm{sub}>/$ Graphene Nanocomposite as Anode Mat... Page 2 of 2

10 wt. \% graphene.

$\mathbf{x}$

See more of: Session 3 - Anodes and Cathodes Posters

See more of: P1: Tuesday Poster Session

See more of: Batteries and Energy Storage

$\leq<$ Previous Abstract | Next Abstract $>>$

\section{Search}

Browse

\section{Browse by Symposium}

\section{At-A-Glance}

\section{Author I ndex}

\section{Meeting Information}

\section{When:}

June $10-14,2014$

Where:

Como, Italy 